\title{
POLA HONORIFIK UNDAK-USUK KEIGO BAHASA JEPANG YANG MENCERMINKAN NILAI UCHI-SOTO SEBAGAI WUJUD IDENTIFIKASI KELOMPOK
}

\author{
Timur Sri Astami \\ Japanese Department, Faculty of Language and Culture, Bina Nusantara University, \\ Jln. Kemanggisan Ilir III No. 45, Kemanggisan/Palmerah, Jakarta Barat 11480, \\ timur_astami@yahoo.com
}

\begin{abstract}
The Japanese has not became a product only, but it becomes more than language product activity, but still relates to culture. Article presents Keigo which is is different from sonkeigo, kenjougo and teineigo. Therefore using keigo such as language user depends on uchi soto and ue shita factors. If using sonkeigo such as opponent more higher than speaker position. Oppenent position as me ue (higher position level) and soto no mono (outsider). And than using kenjougo such as speaker more lower than opponent position. Speaker as uchi (insider) or me shita (low position level).
\end{abstract}

Keywords: honourific pattern, keigo, uchi-soto value, grouping identification

\begin{abstract}
ABSTRAK
Bahasa Jepang tidak hanya sekedar produk tetapi juga merupakan aktivitas kebahasaan yang terkait dengan budaya. Artikel menjelaskan keigo yang berbeda dengan sonkeigo, kenjougo, dan teineigo. Dengan demikian, menggunakan keigo, seperti pengguna bahasa adalah tergantung pada faktor uchi soto dan ue shita. Apabila menggunakan sonkeigo seperti lawan bicara yang lebih tinggi posisinya dari pada si pembicara. Posisi lawan seperti me ue ( posisi lebih tinggi) dan soto no mono (pihak luar). Dan, penggunaan kenjougo seperti si pembicara yang lebih rendah dari lawan bicara. Pembicara sebagai uchi ( pihak dalam) atau me shita ( posisi lebih rendah).
\end{abstract}

Kata kunci: pola honourific, keigo, nilai uchi-soto, identifikasi kelompok 


\section{PENDAHULUAN}

Budaya dan bahasa memiliki keterkaitan yang sangat erat, karena antara budaya dan bahasa merupakan suatu produk ataupun masterpiece mahakarya. Antara budaya dan bahasa timbul disebabkan adanya interaksi manusia di dalamnya. Walaupun bahasa memiliki sifat universal, namun tetap berciri individu dan unik antara bahasa satu dengan yang lain. Demikian halnya dengan budaya, antar budaya satu dengan yang lain tetap memiliki keunikan tersendiri dan tidak sama satu sama lain..

Bahasa yang terwujud dalam kerangka pengetahuan secara linguistik dan gramatikal memiliki landasan akan pemahaman pada penggunaan fungsi bahasa itu sendiri, yang didukung dengan pemahaman discourse (wacana)nya Sebaliknya, budaya yang terwujud dalam kerangka pengetahuan, bersifat individu, yang didukung dengan pemahaman nilai-nilai budaya yang sama. (Sano 1995:81).

Menurut Bartens dalam Alwasilah 2008: 32, bahasa digambarkan seperti dunia melalui sebuah gambaran preposisi secara nyata, yang saling menyesuiakan antara unsure gambar dan realita untuk mendapatkan suatu preposisi yang lengkap.

Agar kesesuain tersebut saling melengkapi, maka tradisi yang berlaku dalam linguistik pun berlaku kesesuain antara parole dan langue nya. Bahkan Saussure pun mengibaratkan suatu bahasa itu bersifat arbitret mana suka antara signifian dan siginfie atau penanda dan petanda yang keduanya saling berkaitan satu dengan yang lain. Sebagai penanda ia tidak akan bermakna apa-apa tanpa didukung penandanya demikian sebaliknya.

Dalam proses berkomunikasi dapat terjadi antara individu dengan individu, individu dengan kelompok, bahkan meluas ke dalam interaksi komunikasi di dalam masyarakat yang lazim disebut dengan masyarakat pengguna bahasa. Ujaran (speech) sebagai suatu cara berkomunikasi sangat mempengaruhi kehidupan individu. Karena setiap individu adalah bagian dari masyarakat. Manusia adalah mahluk sosial yang saling berkomunikasi satu dengan lain. Agar komunikasi dapat berjalan dengan baik, masing-masing individu berusaha untuk saling menyelaraskan pendapat, gagasan, perasaan, keinginan melalui kata-kata. Karena setiap bahasa terdapat banyak kata dan ekpresi, yang seluruhnya bersandar pada keadaan ucapan dan faktor yang melingkupinya baik secara internal maupun eksternal bahasa yang hanya dapat dipahami bila seseorang mengenal serta memahami situasi dan kondisi tersebut (Leech 1993: 19).

Aktivitas berbahasa merupakan perwujudan dari aktivitas sosial masyarakatnya. Dapat dikatakan bahwa praktik berbahasa pada dasarnya adalah melaksanakan praktik secara sosial Karena aktivitas bahasa biasanya tidak hanya berhubungan dengan komunikasi secara linguistik saja, akan tetapi unsur non linguistik turut mempengaruhi dalam kompetensi penguasaan bahasa Adapun lingkup bahasa secara linguistik di mulai dari unsur terkecil hingga luas dan kompleks yakni fonologi, morfologi hingga sintaksis. Sedangkan unsur non linguistik dapat merujuk pada kemampuan non verbal bahasa, yakni sosiolinguistik, paralinguistik hingga pragmatik.

\section{METODE PENELITIAN}

Artikel disusun berdasarkan studi pustaka, yaitu menemukan dan menyeleksi beberapa literature primer dan sekunder, kemudian menyusun menjadi tulisan yang terkait dengan keigo dan uchi-soto dalam bahasa Jepang. 


\section{HASIL DAN PEMBAHASAN}

\section{Uchi to Soto}

Masyarakat Jepang secara umum sejak dari zaman dahulu mengatur dengan ketat sistem kekerabatan. Sendi-sendi keluarga diatur berdasar sistem patrialikal, dimana peran laki-laki dalam keluarga berpengaruh sangat besar. Bahkan berdasar pembagian pekerjaan, posisi urutan anak laki-laki didahulukan dibanding posisi perempuan. Konsep ie yang berdasar patrialikal ini memiliki konsekuensi, satu, laki-laki merupakan penjaga keberlangsungan perekonomian keluarga. Kedua, antar anak lak-laki pertama dan anak-laki-laki kedua secara tidak otomatis sama posisinya, tetap anak lakilaki pertama yang meneruskan tradisi ie tersebut. Ketiga, apabila dalam satu keluarga tidak memiliki anak lak-laki seorang pun, maka ayah sebagai pemegang otoritas tertinggi berhak mengambil menantu laki-laki untuk diangkat sebagai chonan (anak pertama) dan ia harus keluar dari ie nya sendiri untuk membawa nama ie nya yang baru seumur hidupnya. Dapat dikatakan berawal dari sistem ie inilah asal muasal dikotomi istilah uchi dan soto.

Hingga saat ini masyarakat Jepang secara berkesinambungan menjaga dan menerapkan sistem ie secara turun-temurun, walaupun sekarang prakteknya tidak nampak secara riil, namun nilainilai yang dianut masih berlangsung sampai kini. Anggota yang berasal dari ie merujuk istilah uchi yakni pada anggota keluarga satu rumah, bagian anggota dari suatu kelompok dan istri ataupun suami. Atau dapat dikatakan orang luar atau soto yang telah masuk ke dalam uchi dan tmenjadi bagian dari uchi disebut dengan uchi no mono. Karena telah menjadi bagian dari satu uchi, maka secara otomatis berhak dengan sebutan uchi no mono. Sedangkan soto adalah orang di luar rumah, termasuk didalamnya orang lain, ataupun orang yang bukan berasal dari kelompoknya, maka ia disebut dengan soto no mono. Davies (2002:217), menyatakan "The notion of uchi or soto also dominates human relationships throught Japan and people make strong distinctions between inside and oustide in order to feel a sense of security within their groups. Uchi can be defined inside, my house and home, the group taht we belong to and my wife or husband. In contrast soto means the outside, outdoors, other groups an outside home. Groups include one`s home, school an comunity.

Ini menunjukkan bahwa, dalam hubungan antar manusia dalam masyarakat Jepang didominasi dengan uchi atau soto dimana keduanya jelas terlihat nyata sebagai insider bila sesama grupnya dan outsider diluar grupnya. Uchi merujuk pada satu rumah /ie, satu grup, istri atau suami sendiri. Hal ini kontras dengan outside dimana merujuk pada rumah orang lain, grup lain atau ie lain. Termasuk dalam grup adalah satu ie, satu sekolah dan satu komunitas.

\section{Parameter Ragam Keigo}

Keigo adalah ragam bahasa yang digunakan untuk menghormati lawan bicara. Keigo terbagi menjadi sonkeigo, kenjougo dan teineigo. Sonkeigo adalah kata yang digunakan untuk menghormati lawan bicara atau orang yang dibicarakan, yang berkaitan dengan kegiatan atau keadaan lawan bicara dan orang yang dibicarakan. Digunakan pula pada barang milik atau hal yang berhubungan dengan orang itu. Kenjogo adalah suatu ungkapan untuk menunjukkan rasa hormat kepada lawan bicara maupun orang yang menjadi topik pembicaraan dengan cara merendahkan prilakunya sendiri. Orang yang dihormati adalah atasan atau outsider. Kenjogo digunakan juga bila pembicara hendak berbicara tentang insider kepada outsider.

Nakano (dalam Sudjianto,1999:149) menyatakan bahasa keigo dinyatakan dengan parameter usia, status, jenis kelamin, keakraban, gaya bahasa, pribadi atau umum. Maka dalam penggunaan keigo, biasanya orang Jepang mempertimbangkan berdasarkan tiga faktor, yakni pertama, apabila si pembicara lebih muda usianya dan status sosialnya lebih rendah, dia akan menggunakan keigo untuk 
menunjukan rasa hormatnya kepada orang yang lebih senior atau orang yang memiliki status lebih tinggi. Kedua, ketika pembicara tidak memiliki kedekatan hubungan dengan lawan bicara, misalnya ketika pembicara baru pertama kali bertemu dan belum mengenal satu sama lain. Ketiga, hubungan uchi-soto juga harus dipertimbangkan dalam penggunaan keigo. Pihak pembicara seperti keluarga dan perusahaan dianggap sebagai uchi dan kelompok lainnya di luar itu dianggap sebagai soto. Ketika pembicara membahas tentang uchi no hito atau insider dan soto no hito atau outsider, maka insider diperlakukan sebagimana si pembicara itu sendiri. Oleh karena itu walaupun insider lebih senior atau lebih tinggi statusnya, pembicara tidak dapat menggunakan keigo untuk menunjukkan rasa hormatnya kepada insider.

Selain itu, masih menurut Hinata (dalam Sudjianto 2004:195) menyebutkan keefektifan dan peran konkrit pemakaian keigo adalah sebagai berikut. Pertama, sebagai bentuk penghormatan, lawan bicara yang dihormati dapat berupa atasan atau orang yang secara sosial tingkatannya lebih tinggi dari si pembicara. Kedua, sebagai ungkapan formal, sehingga digunakan dalam situasi formal misalnya saat rapat ataupun dalam upacara pernikahan dan sebagainya. Ketiga, untuk menyatakan jarak, diantara pembicara dan lawan bicara yang baru pertama kali bertemu biasaya terdapat jarak psikologis antar keduanya. Sehingga penggunaan keigo dapat menetralkan keadaan saat komunikasi berlangsung. Keempat, untuk menjaga martabat, apabila keigo digunakan dengan tepat maka menunjukkan martabat pembicaranya. Ini berarti si pembicara bukan orang sembarangan, tapi orang yang terdidik dan berkelas

Sejalan dengan hal tersebut, Shibata (2000:7), mengungkapkan:

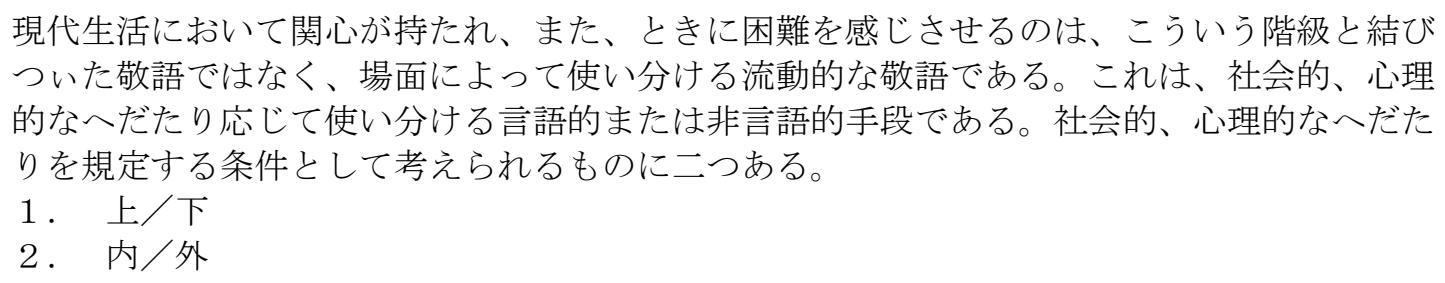

Artinya :

Kehidupan masyarakat modern saat ini, yang berkaitan dengan tingkatan honorifik keigo, tidak hanya berlaku dalam penggunaan keigo sebagai alat berbahasa saja, akan tetapi lebih luas merambah pada konteks komunikasi yang terjalin berdasarkan tempatnya. Maka penggunaan keigo dalam hal ini berkaitan dengan konteks sosial yang termasuk ke dalam terminologi inderect speech (tidak langsung). Hanya ada dua syarat yang memenuhi kriteria komunikasi tersebut yakni, hubungan atasan-bawahan dan insider-outsider.

Merujuk pernyataan Shibatani tersebut, dapat kita pahami bahwa penggunaan ragam keigo yang berkaitan dengan konteks sosial, maka akan mengarah pada masyarakat pengguna bahasa tersebut. Secara tidak langsung dapat dikatakan masyarakat pengguna bahasa yang menggunakan ragam keigo, individu-individu yang berada di dalamnya akan melihat dan memposisikan kapan berlaku sebagai uchi no mono, dan memperlakukan orang lain sebagai soto no mono. Selain itu, pola hubungan atasan-bawahan yang terjadi di dunia kerja, akan memberikan konsekuensi untuk menempatkan inidividu-individu yang berada dalam satu kelompok, maka ia disebut sebagai uchi no mono. Dan sebaliknya sebagai uchi no mono, akan memperlakukan ornag lain di luar kelompoknya yang disebut dengan soto no mono, terlihat jelas dan nyata dalam dunia kerja.

Telah kita ketahui bahwa ketika orang Jepang berkomunikasi satu sama lain, akan terlihat dengan jelas memposisikan dirinya sendiri, apakah dia sebagai bawahan ketika berbicara kepada atasan, ataupun sebagai insider saat berbicara kepada outsider. Oleh karena itu, suatu masyarakat yang menghargai tingkatan undak-usuk dalam kegiatan komunikasinya, maka semakin menunjukkan 
adanya jarak antara pembicara satu dengan yang lainnya. Maka masyarakat Jepang dapt dikatakan termasuk ke dalam masyarakat yang berbudaya high contex (Sano,1995:37). Sebaliknya, semakin sering menggunakan unkapan atau bahasa non formal satu sama lain maka semakin dekat hubungan yang terjalin, dan tidak ada jarak antara pembicara satu dengan yang lainnya. Maka masyarakat ini berbudaya low contex.

Posisi lawan bicara menentukan dalam penggunaan ragaim keigo, masih menurut Shibata ( 2000: 6 ) 相手が自分よりも上かしたか、あるいは、自分と同じ集団内人か、集団外の人かが わからないと、話しにくいものだという経験はだれにもある。その上／下には三つ の主な場合がある。

1 . 年上. 年下

2. 性の上.下 (男。女)

3 . 社会的地位の上. 下

\section{Artinya :}

Posisi lawan bicara apakah sama /lebih tinggi dari si pembicara, ataupun sama-sama berada dalam satu kelompoknya/ diluar kelompoknya, bahkan tidak memahami orang yang berada di luar kelompoknya, semua orang pernah mengalami kesulitan dalam menggunakan ragam keigo. Kemudian hubungan atasan-bawahan terkategori menjadi 3 yakni, pertama, dilihat dari umur (lebih muda atau lebih tua), kedua, jenis kelamin pria atau wanita, ketiga, posisi diri dalam masyarakat (termasuk memiliki pekerjaan yang terhormat seperti guru, dokter misalnya.

Masyarakat yang menganut high contex culture, tentu akan menganggap dan respek kepada orang yang dianggap lebih senior dalam umur, jenis gender dan juga memiliki posisi terhormat dalam masyarakat, sehingga akan lebih dilihat dan dipandang dalam kesehariannya. Maka secara otomatis, penggunaan ragam keigo akan memandang dan melihat pada kategori di atas tersebut.

\section{Ragam Keigo yang Berkaitan dengan Nilai-nilai Uchi - Soto sebagai Wujud Identifikasi Kelompok}

Mizutani (1989:3) menyebutkan bahwa dalam menggunakan keigo yang harus diperhatikan dalam aspek sosial pemakainya, harus melihat faktor-faktor sebagai berikut: keakraban; usia; hubungan sosial; status sosial; jenis kelamin; anggota kelompok; situasi.

Berkaitan dengan nilai-nilai uchi-soto, maka yang akan dibahas dalam tulisan ini, memfokuskan pada point enam, yakni anggota kelompok. Karena dari kelompok ini akan terlihat jelas bagaimana memperlakukan seseorang, bila termasuk ke dalam kelompoknya (uchi), dan bagaimana memperlakukan kepada orang lain (soto).

Masuoka dkk dalam Shibata (2000: 53 ), menyatakan bahwa

日本では家族以外の人との会話で家族を高める表現を使いません。家族をいわば自 分に準じるもの（ウチ）として扱い、それ以外（ソト）の人と区別するわけです。 さらに自分の属する集団、会社、相識などに属する人についても同様にウチとして 扱うことがあります。会社では、社外の人との改まった会話では社長について述べ るときも謙譲語を使うのが普通です。

Artinya:

Di Jepang terhadap keluarga sendiri saat berkomunikasi tidak menggunakan bentuk meninggikan, kecuali kepada orang lain. Sehingga komunikasi yang terjadi dibedakan antara uchi (insider) dan soto (outsider). Selama dalam konteks uchi merujuk pada kesamaan dalam satu kelompok, satu kantor atau perusahaan, satu organisasi. Dalam suatu perusahaan atau 
kantor, saat berkomunikasi dengan orang di luar perusahaan bila orang yang dibicarakan adalah shacho atau kepala kantor sendiri, otomatis akan menggunakan bentuk pola kenjougo, dan hal ini merupakan hal biasa.

Oleh karena itu, pembedaan terlihat jelas antara orang dalam atau uchi no mono, dan orang luar atau soto no mono. Senioritas dalam usia, jenis kelamin ataupun kedudukan, mempengaruhi ungkapan penggunaan ragam keigo. Sehingga sebagai uchi no mono yang memiliki kedudukan lebih tinggi bila berbicara kepada yang lebih muda atau bawahan, biasanya menggunakan bentuk sederhana, dan tergantung pada siapa lawan bicaranya. Walau dalam satu kelompok sekalipun bila lawan bicara lebih tinggi tetap menggunakan bentuk sopan, dan sebaliknya bila lawan bicara lebih rendah kedudukannya dari si pembicara, menggunakan bentuk sederhana (futsuu). Oleh karenanya ketika berbicara dengan orang lain atau sotono mono biasanya menggunakan bentuk kenjougo. berikut ini:

Untuk lebih jelasnya, Shibata (2000:7) membagi pola uchi-soto dan ue-shita dalam bagan

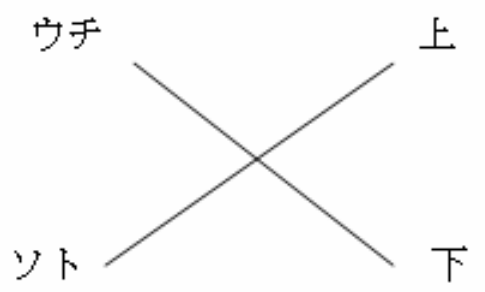

Bagan di atas tersebut dapat dijelaskan, bahwa posisi ue menunjukkan hubungan yang tidak dekat atau bisa dikatakan jauh karena kedudukan yang dimilikinya, menempatkan pada posisi orang yang harus dihormati, sehingga wajar bila menggunakan bentuk sopan (termasuk di dalamnya menggunakan sonkeigo). Sekalipun dalam satu kelompok atau perusahaan yang sama. Hal ini juga berlaku pada soto. Karena soto merupakan orang luar dan memiliki hubungan yang tidak dekat ataupun jauh, sehingga wajar menggunakan ragam sopan (termasuk menggunakan sonkeigo).

Sebaliknya posisi shita menunjukkan yunioritas di dalam suatu kelompok, ini berarti tidak masalah menggunakan ragam sederhana (futsuu atau kenjougo). Demikian halnya dengan uchi, karena menunjukkan hubungan yang dekat dan akrab, sehingga tidak masalah menggunakan ragam sederhana (futsuu atau kenjougo). Masyarakat Jepang yang homogen terpola pada kesamaan dalam kelompok yang menaunginya. Seseorang berada dalam grup yang diikuti maka ia akan menjadi bagian dari kelompok tersebut. Misalnya berada dalam tenisu bu (grup tennis) maka ia akan terikat dengan kelompok tennis itu dan menjadi bagian dari kelompok tersebut. Adapun anggota kelompok dalam masyarakat dapat di kategorikan secara sempit dan luas. Bila dilihat dalam arti sempit maka kelompok itu merujuk pada keluarga inti (nuclear family). Sedangkan dalam arti luas, merujuk pada suatu organisasi. Maka penggunaan keigo yang merujuk pada anggota kelompok dalam arti sempit dan luas terbagi menjadi :

\section{Identifikasi Keluarga}

Apabila berbicara dengan orang lain, dan orang tersebut dianggap sebagai anggota kelompoknya maka menggunakan bentuk sederhana (futsuu). Namun sebaliknya ketika berbicara dengan orang lain yang dianggap bukan angota kelompoknya, maka menggunakan bentuk sopan. Adapun penyebutan berdasar klasifikasi anggota keluarga dapat dilihat pada bagan berikut ini: 


\begin{tabular}{|c|c|c|}
\hline $\begin{array}{c}\text { Keluarga sendiri } \\
\text { 普通 }\end{array}$ & \multicolumn{2}{|c|}{$\begin{array}{c}\text { Kepada Orang lain } \\
\text { 尊敬 }\end{array}$} \\
\hline & $\begin{array}{l}\text { お父さん } \\
\text { sopan }\end{array}$ & $\begin{array}{l}\text { お父さま } \\
\text { lebih sopan }\end{array}$ \\
\hline お母ちゃん、母 & $\begin{array}{l}\text { お母さん } \\
\text { sopan }\end{array}$ & $\begin{array}{l}\text { お母さま } \\
\text { lebih sopan }\end{array}$ \\
\hline お兄ちゃん、兄 & $\begin{array}{l}\text { お兄さん } \\
\text { sopan }\end{array}$ & $\begin{array}{l}\text { お兄さま } \\
\text { lebih sopan }\end{array}$ \\
\hline お姉ちゃん、姉 & $\begin{array}{l}\text { お姉さん } \\
\text { sopan }\end{array}$ & $\begin{array}{l}\text { お姉さま } \\
\text { lebih sopan }\end{array}$ \\
\hline
\end{tabular}

(Mizutani, $2000: 40)$

Apabila A berbicara kepada orang lain, untuk menyebut ayah misalnya, ia akan mengatakan dengan お父ちゃん atau 父. Sebaliknya A berbicara kepada orang lain yakni B, untuk menanyakan kabar ayahnya B, maka A menyatakan お父さん/お父さまは お元気 ですか。Penyebutan untuk ayahnya B, otomatis A akan menyebut dengan bentuk sopan, karena B adalah orang lain, bukan anggota keluarganya atau kelompoknya.

\section{Identifikasi Organisasi}

Identifikasi dengan organisasi, dapat dicontohkan bila pembicaraan dengan kelompok atau angotanya atau bukan anggotanya, tidak terbatas pada anggota keluarga. Akan tetapi lebih merujuk pada organisasi tempat bernaung, dengan kata lain perusahaan tempat ia bekerja.

Contoh, apabila penutur menelepon kepada direktur perusahaan, ia akan mengatakan :
Aさん
秘書
: もしもし、社長さんは いらっしやいますか。
: すみませんが、社長はおりません。

A sebagai orang yang menelepon, menggunakan bentuk sonkeigo, yaitu meninggikan bahasa yang digunakan untuk menghormati lawan bicara. Karena direktur adalah jabatan tertinggi di perusuahaan, sehingga sekertaris pun menggunakan bentuk sopan juga, yakni kenjougo (merendahkan diri dari orang yang dibicarakan, karena orang yang dibicarakan direktur).

Honorifik bahasa Jepang, selain pada penyebutan persona, dapat juga dilihat pada pemilihan verba nya. Yakni dari bentuk sederhana hingga bentuk sopan, futsuugo, sonkeigo dan kenjougo.

Berikut ini pembagian keigo, berdasarkan klasifikasi verba nya (Hinata $2000: 46 \sim 47$ )

\begin{tabular}{|c|c|c|}
\hline 普通語 & 尊敬語 & 謙譲語 \\
\hline いる & $\begin{array}{l}\text { いらっしやる } \\
\text { あいでになる }\end{array}$ & おる \\
\hline する & $\begin{array}{l}\text { なさる } \\
\text { あそばす }\end{array}$ & いたす \\
\hline 行< & $\begin{array}{l}\text { いらっしゃる } \\
\text { おいでになる }\end{array}$ & $\begin{array}{l}\text { 参る } \\
\text { 伺う（お伺い寸る） } \\
\text { 上がる }\end{array}$ \\
\hline 来る & $\begin{array}{l}\text { いらっしゃる } \\
\text { おいでになる } \\
\text { 見える（お見えになる） } \\
\text { お越しになる }\end{array}$ & \\
\hline
\end{tabular}




\begin{tabular}{|c|c|c|}
\hline 普通語 & 尊敬語 & 謙譲語 \\
\hline 言う & おっしやる & $\begin{array}{l}\text { 申す } \\
\text { 申し上げる } \\
\text { 言上する }\end{array}$ \\
\hline 知る & ご存じです & $\begin{array}{l}\text { 存じる } \\
\text { 存じ上げる }\end{array}$ \\
\hline 思う & & 存じる \\
\hline 聞 $<$ & お耳に入る & $\begin{array}{l}\text { 伺う（お伺いする） } \\
\text { 承る } \\
\text { 拝聴する }\end{array}$ \\
\hline 聞かせる & お耳に入れる & \\
\hline 見る & ご覽になる & 拝見する \\
\hline $\begin{array}{l}\text { 見せる } \\
\text { 会う }\end{array}$ & & $\begin{array}{l}\text { お目にかける } \\
\text { ご覧に入れる } \\
\text { お目にかかる }\end{array}$ \\
\hline 借りる & & 拝借する \\
\hline 訪ねる、訪問する & & $\begin{array}{l}\text { 伺う（お伺いする） } \\
\text { 上がる } \\
\text { 参上する }\end{array}$ \\
\hline 食べる、飲む & $\begin{array}{l}\text { 上がる } \\
\text { 召し上がる }\end{array}$ & $\begin{array}{l}\text { いただく } \\
\text { ちょうだいする }\end{array}$ \\
\hline 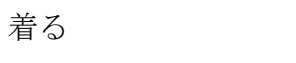 & 召す（お召しになる） & \\
\hline 風邪をひく & お風邪を召す & \\
\hline $\begin{array}{l}\text { 年をとる } \\
\text { 気に入る }\end{array}$ & $\begin{array}{l}\text { お年を召す } \\
\text { お気に召す }\end{array}$ & \\
\hline やる、あげる & & $\begin{array}{l}\text { さしあげる } \\
\text { 進呈する }\end{array}$ \\
\hline もらう & & $\begin{array}{l}\text { いただく } \\
\text { ちょうだいする } \\
\text { たまわる }\end{array}$ \\
\hline くれる & くださる & \\
\hline わかる、引き受ける & & $\begin{array}{l}\text { 承知する } \\
\text { かしこまる }\end{array}$ \\
\hline
\end{tabular}

Selain pola verba ragam keigo (sonkeigo dan kenjougo) yang telah terformat dalam bentuk yang telah disebutkan sebelumnya, karena jumlahnya terbatas, maka dapat digunakan pola sonkeigo dan kenjougo sebagai berikut:

Pertama, sonkeigo

おVマス〜になる

例：お持ちになる

お教えになる 
Akan tetapi bentuk sonkei おVマス〜になる ini hanya dapat digunakan pad akata kerja yang memiliki 2 onsetsu atau lebih, bila memiliki 1 onsetsu saja tidak dapat digunakan. Misalnya seperti 見える、いる、着るなど (Matsuoka 2000: 314).

\begin{tabular}{|lc|}
\hline I $\quad$ グループ & 〜れる \\
\hline II グループ & $\sim ら れ る$ \\
\hline
\end{tabular}

例： 待たれる

教えられる

Kedua, kenjougo

$$
\begin{array}{ll}
\text { おっ } V \text { マス } & \text { する } \\
\text { ご〜Vマス } & \text { する }
\end{array}
$$

例：お待ちする

$$
\text { ご案内する }
$$

\begin{tabular}{|c|c|}
\hline 尊敬語 & 謙譲語 \\
\hline 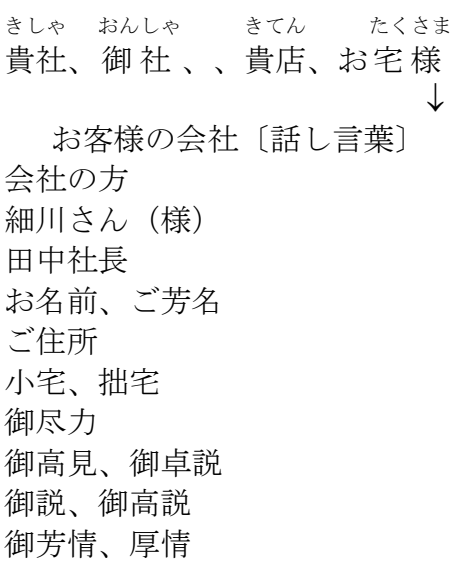 & $\begin{array}{l}\text { とうしゃ いいゃ } \\
\text { 当社、弊社 } \\
\\
\text { わたくしどもの会社（話し言葉） } \\
\text { 会社のもの } \\
\text { 細川 } \\
\text { 社長の田中 } \\
\text { 名前 } \\
\text { 住所 } \\
\text { 貴宅 } \\
\text { 微力 思見 } \\
\text { 私見 } \\
\text { 卑見、愚案 } \\
\text { 博志、志 }\end{array}$ \\
\hline & (Aoki, Matsumoto, Miyazaki 2003 : 88) \\
\hline
\end{tabular}

Selain verba yang terbagi menjadi sonkeigo dan kenjougo, untuk penyebutan nomina terbagi menjadi bentuk sonkeigo dan kenjougo. Pembagian tersebut dapat dilihat pada bagan berikut ini: 


\section{SIMPULAN}

Bahasa sebagai aktivitas adalah perwujudan dari aktivitas sosial masyarakatnya. Sehingga ada kaitan antara masyarakat dan bahasa, karena praktik berbahasa pada dasarnya adalah melaksanakan praktik secara sosial. Pola undak usuk honorifik keigo bahasa Jepang terbagi menjadi sonkeigo dan kenjougo. Sonkeigo adalah kata yang digunakan untuk menghormati lawan bicara atau orang yang dibicarakan, yang berkaitan dengan kegiatan atau keadaan lawan bicara dan orang yang dibicarakan. Digunakan pula pada barang milik atau hal yang berhubungan dengan orang itu. Kenjogo adalah suatu ungkapan untuk menunjukkan rasa hormat kepada lawan bicara maupun orang yang menjadi topik pembicaraan dengan cara merendahkan prilakunya sendiri. Orang yang dihormati adalah atasan atau outsider. Kenjogo digunakan juga bila pembicara hendak berbicara tentang insider kepada outsider. Dalam hubungan antar manusia dalam masyarakat Jepang didominasi dengan uchi atau soto dimana keduanya jelas terlihat nyata sebagai insider bila sesama grupnya dan outsider diluar grupnya. Uchi merujuk pada satu rumah /ie, satu grup, istri atau suami sendiri. Termasuk dalam grup adalah satu ie, satu sekolah dan satu komunitas. Sedangkan soto atau outside merujuk pada rumah orang lain, grup lain atau ie lain.

Posisi ue menunjukkan hubungan yang tidak dekat atau bisa dikatakan jauh karena kedudukan yang dimilikinya, menempatkan pada posisi orang yang harus dihormati, sehingga menggunakan bentuk sopan (termasuk di dalamnya menggunakan sonkeigo).. Hal ini juga berlaku pada soto. Karena soto merupakan orang luar dan memiliki hubungan yang tidak dekat ataupun jauh, sehingga menggunakan ragam sopan (termasuk menggunakan sonkeigo). Sebaliknya posisi shita menunjukkan yunioritas di dalam suatu kelompok, ini berarti tidak masalah menggunakan ragam sederhana (futsuu atau kenjougo). Demikian halnya dengan uchi, karena menunjukkan hubungan yang dekat dan akrab, sehingga tidak masalah menggunakan ragam sederhana (futsuu atau kenjougo). Identifikasi kelompok terbagi menjadi, Identifikasi keluarga, apabila berbicara dengan orang lain, dan orang tersebut dianggap sebagai anggota kelompoknya maka menggunakan bentuk sederhana (futsuu). Namun sebaliknya ketika berbicara dengan orang lain yang dianggap bukan angota kelompoknya, maka menggunakan bentuk sopan; Identifikasi Organisasi, yakni lebih merujuk pada organisasi tempat bernaung, dengan kata lain perusahaan tempat bekerja. Sehingga kepada orang lain menggunakan ragam sopan atau kenjougo.

\section{DAFTAR PUSTAKA}

Alwasilah, Chaedar. (2008). Filsafat Bahasa dan Pendidikan. Bandung: Rosda

Aoki, Teru, dkk. 2003. Tadashii Keigo no Tsukaikata. Tokyo: JMAM

Davies, Roger J \& Osamu Ikeno .2002. The Japanese Mind. New York : Tuttle Publishing

Djajasudarma,F.T.2001. Bahasa Daerah dan Budi Pekerti Bangsa. Makalah Seminar Sosialisasi Peraturan Daerah No 6 Tahun 1996 dalam Pelaksanaan Otonomi Daerah. 16 April 2001. Bandung :PPS Unpad

Leech, Geoffrey. 1993. Prinsip-prinsip Pragmatik. Jakarta: Universitas Indonesia

Masakazu.2003.Gengogaku Nyumon.Tokyo: Aruku

Moriyama, Takuro. 2003. Komyunikeeshon Chikara wo Migaku. Tokyo : NHK Books 
Ogawa, Yoshiko.2003. Keigo wo Chuushin Toshita Taijin Kankei no Hyougen Tokyo: 3A Nettwork Sano, Masakazu dkk. 1995. Ibunka Rikai no Sutoratejii. Tokyo : Daishukan Shoten Shibata, Takeshi, dkk.2000. Keigo Semina A-Z. Tokyo : Kashihisha

Sudjianto.Ahmad Dahidi.2006.Pengantar Linguistik Bahasa Jepang.Kesaint Blanc

Tanaka, Makino, Shigekawa,Mikogami, Koga, Sawada dan Shinya Makiko.2001. Minna no Nihonggo II. PT. Pustaka Lintas Budaya

Tatematsu, Kikuko,dkk . 2000. Writing Letter in Japanese. Tokyo: Japan Times 